\title{
RELATIONSHIP OF FORCE PLATFORM WITH THE CLINICAL BALANCE EVALUATION SYSTEMS TEST IN OLDER ADULTS
}

\author{
RELAÇÃO DA PLATAFORMA DE FORÇA COM O TESTE CLÍNICO \\ DE AVALIAÇÃO DE EQUILÍBRIO (BESTEST) EM IDOSOS
}

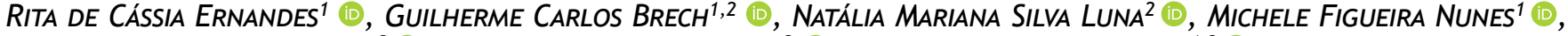

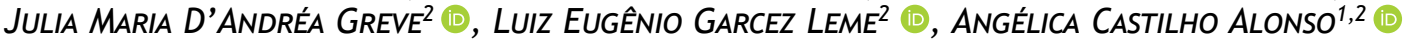 \\ 1. Universidade São Judas Tadeu, Department of Graduation in Aging Science, São Paulo, SP, Brazil. \\ 2. Universidade de São Paulo, School of Medicine, Institute of Orthopedics and Traumatology, (IOT/FMUSP), Sao Paulo, SP, Brazil.
}

\section{ABSTRACT}

The aging process can alter the organization of postural control causing instability; literature shows several equipment and clinical tests whose purpose is to measure postural balance, involving different protocols and methodologies. Objective: To evaluate postural balance during the task to walk over the force platform (turn and return) and its relationship with clinic balance test (BESTest) in older adults. Methods: 60 older people of both sexes, aged 60 to 79 years, were tested in the force platform (NeuroCom Balance) and BESTest to evaluate postural balance. Results: negative correlations were found when comparing domains of the clinical test with stabilometric parameters in time and velocity variables of the tests Step/Quick turn. The highest correlations were in the total score (time spent to perform the task -0.41 , and in the velocity left side -0.33 /right side -0.43 ), as well as in the stability limit (time spent to perform the task left side $-0.34 /$ right side -0.37 , and the equilibrium velocity left side $-0.37 /$ right side -0.43$)$. Conclusion: There are slim correlations between the clinical test and force platform variables, showing that each test measures different parameters. Level of evidence II, Diagnostic study - investigating a diagnostic test.

Keywords: Postural Balance. Gait. Aged.

\section{RESUMO}

O processo de envelhecimento pode alterar a organização do controle postural causando instabilidade. Na literatura há vários equipamentos e testes, envolvendo protocolos e metodologias diversas, com a finalidade de mensurar o equilíbrio corporal. Objetivo: Avaliar o equilíbrio postural e analisar a correlação entre os dados da plataforma de equilíbrio e do teste clínico (BESTest) em idosos. Métodos: Foram avaliados 60 idosos de ambos os sexos, com idade de 60 a 79 anos. Para avaliação do equilíbrio postural foi utilizada a plataforma de força (NeuroCom Balance) e o BESTest. Resultados: Correlações negativas foram encontradas quando comparados os domínios do teste clínico (BESTest) com parâmetros estabiliométricos nas variáveis tempo, velocidade e impacto dos testes Step/Quick turn. As maiores correlações foram no score total (tempo gasto para realizar a tarefa $L E-0,41$, e na velocidade do equilíbrio $L E-0,33 / L D-0,43)$, assim como no limite de estabilidade (tempo gasto para realizar a tarefa $L E-0,34$ ) $L D$ - 0,37, e a velocidade do equilíbrio $L E-0,37 / L D-0,43)$. Conclusão: Há poucas e fracas correlações entre o teste clínico e as variáveis do teste Step/Quick turn da plataforma de força, mostrando que cada teste mede parâmetros diferentes. Nível de Evidência II, Estudos diagnósticos - investigação de exames para diagnóstico.

Descritores: Equilíbrio Postural. Marcha. Idoso.

Citation: Ernandes RC, Brech GC, Luna NMS, Nunes MF, Greve JMD, Leme LEG, Alonso AC. Relationship of force platform with the clinical balance evaluation systems test in older adults. Acta Ortop Bras. [online]. 2020;28(3):111-3. Available from URL: http://www.scielo.br/aob.

\section{INTRODUCTION}

Postural balance is the maintenance of the center of gravity within the base support of the body. ${ }^{1}$ The aging process leads to changes in the sensory systems involving postural balance and consequently an increase in number of falls. ${ }^{2}$

There are several equipment, clinical tests and scales, developed to evaluate postural balance. Health professionals are frequently looking for clinical tests that could have the same results as gold standard instruments that assess postural balance, such as the force platform, to become useful in clinical practice. However, the biomechanics industry creates more high cost sensitive equipments. ${ }^{3}$ The NeuroCom Balance Master ${ }^{\circledR}$ provides objective assessment of the sensory and voluntary motor control of balance with visual biofeedback, which enables objective assessment of performance in essential activities of daily living. Previous studies measuring the stabilometric parameters demonstrated that the equipment is reliable ${ }^{4}$ and provides accurate measurements of the postural balance in different groups. ${ }^{5-6}$ The Balance Evaluation Systems Test (BESTest) is

All authors declare no potential conflict of interest related to this article.

The study was conducted at Universidade São Judas Tadeu and developed in partnership with the Laboratory of Movement Studies of the Institute of Orthopedics and Traumatology at the Clinic Hospital of the Universidade de São Paulo School of Medicine (HCFMUSP).

Correspondence: Guilherme Carlos Brech. Rua Dr. Ovídio Pires de Campos, 333, 2o andar, São Paulo, Brazil, 04503010. guibrech@gmail.com 
used by clinicians to categorize balance into six underlying systems that may constrain balance, being the first test to include a clinical method for assessing postural responses to external disturbances, whose purpose is to evaluate the postural balance..$^{7-8}$

Both systems have their advantages and disadvantages: the Balance System platform is a more accurate, but costly equipment that requires a trained professional to perform data acquisition; on the other hand, the BESTest is low cost and provides reliable measures related to postural balance, and it can be applied anywhere with a clinical or scientific purpose. These tests are indicated to guide clinical treatment strategies for fall prevention protocols. As such, an analysis of the relationship between the force platform and this clinical test is justified, in view of the prognosis of the postural balance responses resulting from this comparison, whether or not the professionals involved use them with more precision and specificity, and consequently to design more efficient rehabilitation programs.

Thus, the aim of this study was to evaluate postural balance during the task to walk over the force platform (turn and return) and its relationship with clinic balance test (BESTest) in older adults.

\section{METHODS}

This was a cross-sectional study approved by the Ethics Committee of the Universidade São Judas Tadeu (registration number: 60952116.4.0000.0089) and developed in partnership with the Laboratory of Movement Studies of the Universidade de São Paulo School of Medicine and the Universidade São Judas Tadeu. All participants provided a written informed consent.

\section{Subjects}

Sixty older adults of both sexes between 60 and 79 years old were evaluated. The subjects were recruited from the Integrated Health Center (CIS), endocrinology department of the Universidade Anhembi Morumbi. The inclusion criteria were absence of foot ulcers and/or partial and total lower limb amputations; disease or functional impairment of any system: auditory, vestibular, proprioceptive, neurological, musculoskeletal; no use of medications that could affect the postural balance; and present normative parameters in the cognitive test (MoCA). Exclusion criteria: if for any reason, subjects could not perform any of the proposed tests.

\section{Measurements}

The following data were initially collected during the interviews: age, MoCA, education (years of education), weight, height, and body mass index (BMI).

Balance Evaluation Systems Test (BESTest) containing 27 items, with a total of 36 tasks organized in six sections (biomechanical constraints, stability limits, postural responses, anticipatory postural adjustments, sensory orientation, dynamic balance during gait, and cognitive), was used to evaluate postural balance. All domains followed the protocol established by the translation and adaptation to Brazilian portuguese. ${ }^{9}$

The postural balance assessment (posturography) was performed on the NeuroCom Balance Master ${ }^{\circledR}$ force platform system
(NeuroCom International, Inc., Clackamas, OR, USA). The system uses a fixed $18 \mathrm{in} . \AA \sim 60$ in. dual force plate to measure the vertical forces exerted by the patient's feet. ${ }^{9-12}$

The test is a functional balance evaluation, where older adults were advised to walk on the platform, rotate 180 degrees, and return to the starting place ("Step/Quick Turn" task),first to the left and then to the right, repeating three times in a 30 second interval on each side. This assessment quantifies two movement characteristics as the patient takes two steps forward, quickly turns $180^{\circ}$, and steps back to the starting point. The measured parameters are turn-time (Time spend for the task) expressed in sec; and turn-sway velocity (Balance velocity) expressed in \%.

\section{Statistical analysis}

Data were stored in the SPSS 24.0 program and presented by means and standard deviation. The Kolmogorov-Smirnov test was performed to verify if the variables adjusted to normality. The Spearman correlation test was used to assess the bivariate correlation between measures, and a 5\% level of significance was adopted throughout the analysis.

\section{RESULTS}

Sample characterization regarding age and anthropometric data, education level and cognitive conditions are presented in Table 1.

\begin{tabular}{|c|c|c|c|}
\hline & Mean (SD) & Minimum & Maximum \\
\hline Age (years) & $7.03(5.51)$ & 60 & 79 \\
\hline MoCA & $23.35(3.15)$ & 16 & 26 \\
\hline Education (years) & $11.5(4.73)$ & 1 & 15 \\
\hline \multicolumn{4}{|l|}{ Anthropometry } \\
\hline Body weight $(\mathrm{kg})$ & $72.37(13.16)$ & 46.80 & 66.30 \\
\hline Height (m) & $1.62(0.09)$ & 1.43 & 1.69 \\
\hline BMI $\left(\mathrm{kg} / \mathrm{m}^{2}\right)$ & 27.66 (3.78) & 18.70 & 34.70 \\
\hline
\end{tabular}

When compared, the clinical test data (BESTest) and the stabilometric parameters, the total BESTest score (the sum of its six domains) and the stability limit, showed a negative correlation between the time spent to perform the "Step/Quick Turn" task and the speed on both sides (right and left) (Table 2).

The Biomechanical Restrictions domain showed negative correlation with the time spent to perform the task on the left side, while "anticipatory transition" showed negative correlation with the time spent to perform the task on both sides.

The reactive test showed a negative correlation only in the time spent to perform the task on the right side, presenting no significant differences in the other data. Sensory orientation showed negative correlation in balance velocity on the right side, while "gait stability" showed negative correlation in the time spent to perform the "Step/ Quick Turn" task on the right side (Table 2).

Table 2. Correlation between clinical test (BESTest) and stabilometric parameters in the force platform.

\begin{tabular}{|c|c|c|c|c|c|c|c|}
\hline Step/Quick turn & BESTest total & $\begin{array}{c}\text { Biomechanical } \\
\text { Restrictions }\end{array}$ & Stability Limits & $\begin{array}{l}\text { Anticipatory } \\
\text { Transition }\end{array}$ & Reactive & $\begin{array}{c}\text { Sensory } \\
\text { Orientation }\end{array}$ & Gait Stability \\
\hline Time spend for the task LS (sec) & $-0.36(0.00)^{\star *}$ & $-0.24(0.05)^{*}$ & $-0.34(0.00)^{\star *}$ & $-0.25(0.05)^{*}$ & $-0.17(0.19)$ & $-0.11(0.37)$ & $-0.23(0.07)$ \\
\hline Time spend for the task RS (sec) & $-0.41(0.00)^{\star \star}$ & $-0.21(0.10)$ & $-0.37(0.00)^{* \star}$ & $-0.24(0.06)$ & $-0.26(0.04)^{*}$ & $-0.21(0.10)$ & $-0.30(0.01)^{*}$ \\
\hline Balance velocity - LS $(\% / \mathrm{s})$ & $-0.33(0.10)$ & $-0.16(0.22)$ & $-0.37(0.00)^{* *}$ & $-0.15(0.24)$ & $-0.15(0.25)$ & $-0.19(0.13)$ & $-0.17(0.18)$ \\
\hline Balance velocity - RS $(\% / \mathrm{s})$ & $-0.43(0.00)^{\star *}$ & $-0.15(0.22)$ & $-0.43(0.00)^{* *}$ & $-0.22(0.08)$ & $0.24(0.06)$ & $-0.30(0.01)^{*}$ & $-0.31(0.01)^{*}$ \\
\hline
\end{tabular}




\section{DISCUSSION}

This study found that the tests results (clinical and force platform) had low to moderate association among them, possibly because the stabilometric parameters captured differences in functional performance abilities, whereas the BESTest (clinical method) evaluated postural responses to external disturbances. Both are multifaceted, and the nature of each task demonstrates the results of this study. The BESTest focuses on the variety of disability dimensions ${ }^{8}$ and guides treatment decision; while the force platform (Balance Master) provides quantification of the postural balance index ${ }^{13}$ with a better precision to demonstrate small disturbances and postural adjustments based on the total oscillation of the platform. ${ }^{11-4}$ One of the most common tasks of the activities of daily living (ADL) and used throughout all the domains of BESTest, "Step/Quick Turn" is a challenging test because stepping must be tightly coordinated, and head rotation changes visual and vestibular inputs. To turn around, the patient must anticipate the action, decelerate the forward progression of the COG, alter the stepping pattern, then re-initiate gait in the opposite direction. The change in direction must be anticipated so that forward COG progression can be sufficiently decelerated to allow the change in direction, but not stopped, or else momentum that can assist with the turn will be lost. A change in step pattern is also required: the most efficient one is pivot on the toes of the lead foot, while the trailing foot does not advance, as it would in taking a step forward, but pivots in place and is immediately ready to accept the body weight as it begins to travel in the opposite direction. ${ }^{10}$

We found several studies comparing functional and physical performance measures with ones based on stabilometric parameters, as well as between clinical tests, scales with force platform parameters, and kinetic and posturographic measurements, ${ }^{7,11,14-17}$ but these results must be carefully analyzed, considering methodological differences and application in different groups.

The time (s) and oscillation velocity $(\% / \mathrm{s})$ variables obtained by the "Step/Quick Turn" test on the force platform, used to measure stability in a $180^{\circ}$ turn, are negatively correlated (low to moderate) to almost all domains of BESTest. Thus, clinical balance tests can discriminate subjects with large differences in posture maintenance, ${ }^{7-17}$ but not identify small postural adjustments, which can be done with equipment such as the force platform. ${ }^{14}$ If we are able to identify typical movements that demonstrate a poor postural balance (risk of fall) involving walking and a $180^{\circ}$ turn, the maneuver becomes challenging to older people compared to walking straight, because the body remains outside the base of support in most of the support phase of the gait. ${ }^{18-19}$

During the test, the patients were instructed to complete it as quickly as possible, where low scores (faster turns) are good, while higher scores (slower turns) are worse. Patients may not be able to safely turn quickly if they cannot control the moving COG over the small base of support (pivot foot) and must instead resort to the slower strategy of taking multiple steps to turn around. This compensatory strategy allows for double support time, sacrificing speed for stability. Patients may not be able to pivot due to ankle weakness, non-coordination, or sensory abnormalities (visual/ vestibular). Thus, the negative correlations found between the test and the clinical evaluations of postural balance demonstrate that the higher the score (higher score = better balance) the shorter were the time and speed (shorter time and lower velocity = better balance) spent on the task.

Although our findings are limited and need further studies that include methodological investigations on postural balance measures within the parameters analyzed, this study indicates that, while the clinical test and the force platform provided different data about balance, they complement each other and should be used together to provide more relevant information to the understanding of postural balance. Thus, this study contributed to helping health professionals detect mechanisms essential for the field of gerontology.

\section{CONCLUSION}

Clinical tests (BESTest) are poorly to moderate correlated with the Step Quick/Turn test on the Balance Master force platform.

\section{ACKNOWLEDGMENT}

This study was financed in part by the Coordenação de Aperfeiçoamento de Pessoal de Nível Superior - Brazil (CAPES) - Finance Code 001.

AUTHORS' CONTRIBUTIONS: Each author contributed individually and significantly to the development of this article: RCE: substantial contribution to the conception and writing of the study; final approval of the manuscript; GCB: critical review of the intelectual content and final approval of the manuscript; NMSL: Acquisition and final approval of the manuscript. MFN: writing of the study and final approval of the manuscript; JMDG: critical review of the intelectual content and final approval of the manuscript; LEGL: critical review of the intelectual content and final approval of the manuscript; ACA: statistical analysis; data interpretation and final approval of the manuscript.

\section{REFERENCES}

1. Alonso AC, Luna NMS, Mochizuki L, Barbieri F, Santos S, Greve JMD. The influence of anthropometric factors on postural balance: the relationship between body composition and posturographic measurements in young adults. Clinics (Sao Paulo). 2012;67(12):1433-41.

2. Drzał-Grabiec J, Snela S, Rykała J, Podgórska J, Banaś A. Changes in the body posture of women occurring with age. BMC Geriatr. 2013;13:108.

3. Brech GC, Luna NMS, Alonso AC, Greve JMD. Positive correlation of postural balance evaluation by two different devices in community dwelling women. MedicalExpress. 2016;3(2):M160203.

4. Carter ND, Khan KM, McKay HA, Petit MA, Waterman C, Heinonen A, et al. Community-based exercise program reduces risk factors for falls in 65- to 75-year-old women with osteoporosis: randomized controlled trial. CMAJ. 2002;167(9):997-1004

5. Schilling RJ, Bollt EM, Fulk GD, Skufca JD, Al-Ajlouni AF, Robinson CJ. A quiet standing index for testing the postural sway of healthy and diabetic adults across a range of ages. IEEE Trans Biomed Eng. 2009;56(2):292-302.

6. Riemann BL, Davies GJ. Limb, sex, and anthropometric factors influencing normative data for the biodex balance system SD athlete single leg stability test. Athl Train Sport Heal Care. 2017;5(5)224-32.

7. Horak FB. Postural orientation and equilibrium: what do we need to know about neural control of balance to prevent falls? Age and Ageing. 2006;35 Suppl 2:ii7-ii11.

8. Horak FB, Wrisley DM, Frank J. The balance evaluation systems test (BESTest) to differentiate balance deficits. Phys Ther. 2009;89(5):484-98.

9. Mendonça DLC, Alonso AC, Greve JMD, Garcez-Leme LE. Assessment of the quality of life, muscle strength, and dynamic balance of elderly Kendo players. Clinics. 2017;72(11):661-6.
10. NeuroCom International. Balance Master System Operator's Manual, version 8.1. Clackamas: NeuroCom; 2003.

11. Brech GC, Alonso AC, Luna NMS, Greve JM. Correlation of postural balance and knee muscle strength in the sit-to-stand test among women with and without postmenopausal osteoporosis. Osteoporos Int. 2013;24(7):2007-13.

12. Brech G, Andrusaitis S, Vitale G, Greve JMDA. Correlation of disability and pain with postural balance among women with chronic low back pain. Clinics (Sao Paulo). 2012;67(8):959-62.

13. Paterno MV, Myer GD, Ford KR, Hewett TE. Neuromuscular training improves single-limb stability in young female athletes. J Orthop Sports Phys Ther. 2004;34(6):305-16.

14. Lin D, Seol H, Nussbaum MA, Madigan ML. Reliability of COP-based postura sway measures and age-related differences. Gait Posture. 2008;28(2):337-42

15. Holbein-Jenny MA, McDermott K, Shaw C, Demchak J. Validity of functional stability limits as a measure of balance in adults aged 23-73 years. Ergonomics. 2007;50(5):631-46

16. Nejc S, Jernej R, Loefler S, Kern H. Sensitivity of body sway parameters during quiet standing to manipulation of support surface size. J Sport Sci Med. 2010;9(3):431-8.

17. Franchignoni F, Horak F, Godi M, Nardone A, Giordano A. Using psychometric techniques to improve the balance evaluation systems test: the mini-BESTest. J Rehabil Med. 2010;42(4):323-31.

18. Akram SB, Frank JS, Chenouri S. Turning behavior in healthy older adults: Is there a preference for step versus spin turns? Gait Posture. 2010;31(1):23-6.

19. Fino PC, Lockhart TE, Fino NF. Corner height influences center of mass kinematics and path trajectory during turning. J Biomech. 2015;48(1):104-12. 